\title{
Agent- and Cloud-Supported Geospatial Service Aggregation for Flood Response
}

\author{
Xicheng Tan ${ }^{\mathrm{a}}$, Liping Di ${ }^{\mathrm{b},}$,, Meixia Deng ${ }^{\mathrm{b}}$, Aijun Chen ${ }^{\mathrm{c}}$, Ziheng Sun ${ }^{\mathrm{b}}$ Chen Huanga ${ }^{\mathrm{a}}$, Yuanzheng Shao ${ }^{\mathrm{a}}$, Xinyue $\mathrm{Ye}^{\mathrm{c}}$ \\ ${ }^{a}$ International School of Software, Wuhan University, 430079, Wuhan, China - xctan@whu.edu.cn \\ b Department of Geography and GeoInformation Science, George Mason University, Fairfax, VA 22030, USA, ldi@gmu.edu \\ ${ }^{c}$ NOAA/NGS, 1315 East-West Highway, Silver Spring, MD 20910-3282 \\ ${ }^{\mathrm{d}}$ Department of Geography, Kent State University, Kent, OH, 44242, USA
}

KEY WORDS: Flood Response, Geospatial Service, Service Aggregation, Open Geospatial Consortium, Cloud, Agent

\begin{abstract}
:
Flooding caused serious losses in China in the past two decades; therefore, responding to and mitigating the impact of flooding is a task of critical importance. The traditional flood response process is usually very time-consuming and labor-intensive. The ServiceOriented Architecture (SOA) -based flood response is a method with low efficiency due to the large volume of geospatial data transfer, and this method cannot meet the real-time requirement of a rapid response to flooding. This paper presents an Agent- and Cloud-supported geospatial service aggregation to obtain a more efficient geospatial service system for the response to flooding. The architecture of this method is designed and deployed on the Cloud environment, and the flooding response prototype system is built on the Amazon AWS Cloud to demonstrate that the proposed method can avoid transferring large volumes of geospatial data or Big Spatial Data. Consequently, this method is able to achieve better performance than that of the SOA-based method.
\end{abstract}

\section{INTRODUCTION}

Flooding is one of the most frequent and serious disasters in China, and it is crucial to conduct research on flood prevention and disaster reduction. To save lives and reduce economic loss during flooding, the Flood Control and Drought Relief Office (FCDRO) must make rapid emergency decisions and take effective actions. Traditionally, if there is a flood emergency, FCDRO needs to collect all of the required data from various sources and gather the related personnel to discuss and devise the best flood response scheme. FCDRO will communicate the suggested flood control plan with all of the involved authorities and organizations one by one in a top-down process. Finally, all of the involved members will conduct the flood control tasks according to the scheme. Unfortunately, the process is usually very time-consuming and labor-intensive, and real-time decision making is not possible.

It has been proven that constructing an effective flood prevention and disaster reduction assistant system can result in rapid decision making during flooding. In the 1990s and early 2000s, many Client/Server (C/S)- and Browser/Server (B/S)based disaster prevention and reduction systems were built to assist policy making. These systems manually collect all of the required data into the database of the server in advance; therefore, it is difficult for these systems to acquire the latest data and use distributed geospatial data. It is hard for these systems to adopt the latest and improved algorithms or models. Consequently, the $\mathrm{C} / \mathrm{S}$ - or $\mathrm{B} / \mathrm{S}$-based disaster prevention and reduction systems still cannot acquire rapid and correct decisions especially during an emergency.

Consequently, the Service-Oriented Architecture- (SOA) based method has played a great role in disaster prevention and reduction in decision making. A flexible SOA-based framework was proposed in environmental crisis management decision support to assist decision making in case of an emergency (Vescoukis et al., 2012). Cloud computing and the SOA method were explored to address the problem of communication among

\footnotetext{
Corresponding author
}

the authorities in the rescue process during an emergency (Lehto et al., 2012). The use of the utility cloud services and SOA in public protection and disaster relief (PPDR) operations was also investigated, and the benefits of the standardized PPDR SOA were evaluated (Rajamäki et al., 2014). Furthermore, based on the SOA architecture, the OGC specifications are utilized to aggregate the geospatial services and chain geospatial services to conduct the flood response and other applications (Di, 2005; Sayar et al., 2005; Di et al., 2006; Deng and Di, 2010; Yu et al., 2012).

Cloud computing refers to the use of hardware and software that are delivered as a service over a network (Armbrust, 2010, Yang, 2011) and has been utilized in geoscience (Yang, 2011; Huang, 2013; Huang, 2013; Yang, 2013; Yue, 2012; Chen, 2012). Cloud-based methods also have been utilized to optimize SOA-based disaster response.

The Agent-based methods have been explored in the past decade (Gray, 2002) and has become very popular and played important roles in Geoscience research (Dijkstra, 2001; Muller, 2009; Tong, 2011). By combining Cloud computing and a Mobile Agent, the agents can participate in the construction of the geospatial service chain, and as a result the efficiency of the geospatial service chain, it has been highly optimized (Tan, 2015).

This research proposed an optimized method, which uses the Agent-generated geospatial service to optimize the service aggregation and to obtain an efficient flooding response. Compared to the traditional SOA-based method, this method can optimize the efficiency of geospatial service aggregation of the distributed environment.

\section{FLOODING RESPONSE MODEL}

We take the flooding response of the Yangtze River basin as a case study to verify the feasibility of Agent- and Cloudsupported service aggregation method. To reduce the flood pressure of the Yangtze River, dikes were built to separate some zones, which were named flood-diversion zones (FDZ). When the flood level exceeds the warning level, the sluices will be elevated according to the order of FCDRO to discharge the 
flood into the chosen FDZs. However, one problem is that there are still many flood-stranded residents, crops, industrial factories and other properties in the large FDZs. Thus, the decision makers need to consider flood-affected population evacuation, the transfer of property, the emergency supply of materials and the agricultural loss of the FDZs. We introduce the current flooding response manner of work and design a flooding response model for automatic processing.

Disaster prevention and reduction in the Yangtze River basin of China is a systematic project, which involves many departments, institutions and organizations including Flood Control and Drought Relief Office (FCDRO), Ministry of Land and Resources (MLR), Ministry of Transportation (MT), Ministry of Agriculture (MA), Academic and research organizations (ARO), Bureau of statistics (BS), Disaster and Emergency Relief Organization (DERO), Medical Aid Organization (MAO), Disaster Substance Support Organization (DSSO) and Volunteer Organization (VO).

During the flooding, FCDRO makes decisions for rescuing the flood-effected population, and offers necessary medical care aid, tents, foods and water, as well as analyze the social economic loses, e.g. agriculture loss, industrial loss, property loss and etc. According to the duty of FCDRO, We designed a Flooding Response Model as shown in Figure 1.

We designed this model according to the current work manner of the flooding response. The model includes the requisite analysis during flooding as shown in Figure 8. The decision makers and the participators can execute the model during flooding, or at any other time to simulate the flood response analysis. The procedures of the model are listed as follows:

(1) Flood level data input: when the flood level is input into the system the composite service will begin to run;

(2) Submerged area analysis: once the flood level data are input, the submerged area of all the related FDZs will be analyzed depending on the flood level input and the DEM;

(3) Crops extraction analysis: the crops will be extracted based on remote sensing data of the flooding area, and then the submerged crops will be figured out depending on the submerged area and the extracted crops via overlap analysis;

(4) Flood-effected population analysis: the number and locations of the population involved in the flood and who need to evacuate to safe places is analyzed;

(5) Refuge location analysis: depending on the result of involved population analysis, the DEM analysis and the safe area data, the proper refuge locations will be selected;

(6) Evacuation route analysis: the evacuation route depending on the DEM data, road, locations of population and refuges is analyzed;

(7) The schedule of rescue workers: According to the involved population and the refuge location, determine the schedule of the rescue workers;

(8) The schedule of the emergency supply materials: according to the stranded residents and the refuge location, the schedule of the emergency material supply will be made;
(9) The schedule of the medical care resources: According to the population of stranded residents and the refuge location, a plan for the scheduling of the medical care resources will be made;

(10) The schedule of the volunteer: according to the population of stranded residents and the refuge locations, the schedule of the volunteer will be made;

(11) Submerged crops analysis and agriculture lost statistic: based on the result of submerged area analysis and crops extraction analysis, the loss of agriculture will be determined.

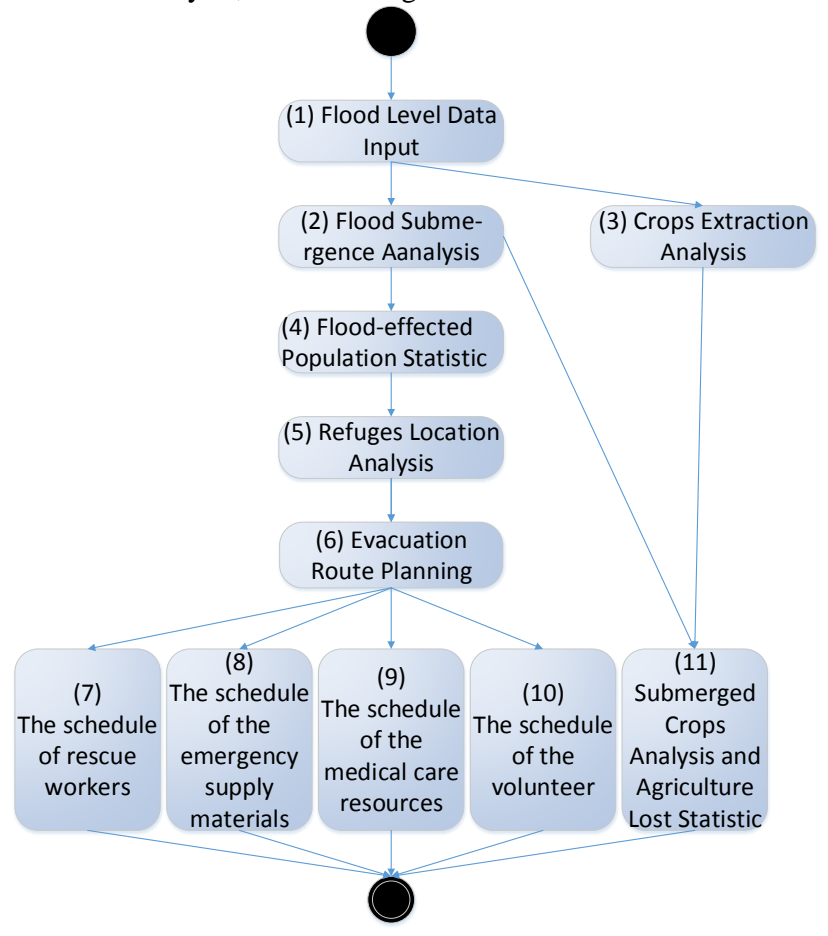

Figure 1 Flood Response Model

\section{AGENT- AND CLOUD-SUPPORTED GEOSPATIAL SERVICE AGGREGATION ARCHITECTURE}

To build the Agent- and Cloud-supported flooding response on the Cloud, the logical structure of the present study has 5 tiers as shown in Fig. 2.

The hardware tier is the infrastructure of the Cloud computing and the upper applications. This tier provides the fundamental computing resources such as CPU, GPU, Memory, etc. The large storage and high speed network are also provided to support the storage and transfer large volumes of spatial data on the Cloud.

The Cloud computing tier delivers the resources as a service in the distributed network. Based on IaaS, Hardware resources (e.g., CPU, GPU, Memory, Storage, Network, etc.) can be virtualized to virtual machines (VM) or virtual clusters and disks can be converted into a network storage service. In addition, a virtual network service (e.g., Virtual Private Network) can be provided. These virtual resources support geospatial services. PaaS offers the OS and the basic Cloud develop environments for the users, and by the PaaS services, the automatic adjustment of the number of the VM or the scale of the Virtual Cluster is achievable and the Agent fundamental 
environment can be deployed automatically. SaaS offers the requisite software on the Cloud such as the geospatial service software (e.g., Geoserver, 52north, etc.), security software, etc.
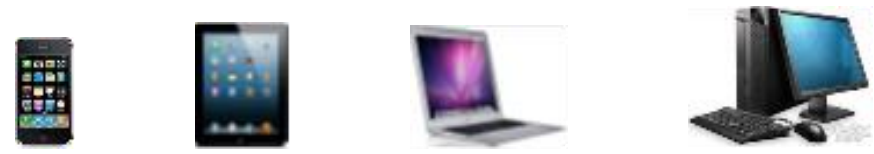

\section{Applications: Emergency Response, Climate Change, Forecast, etc.}

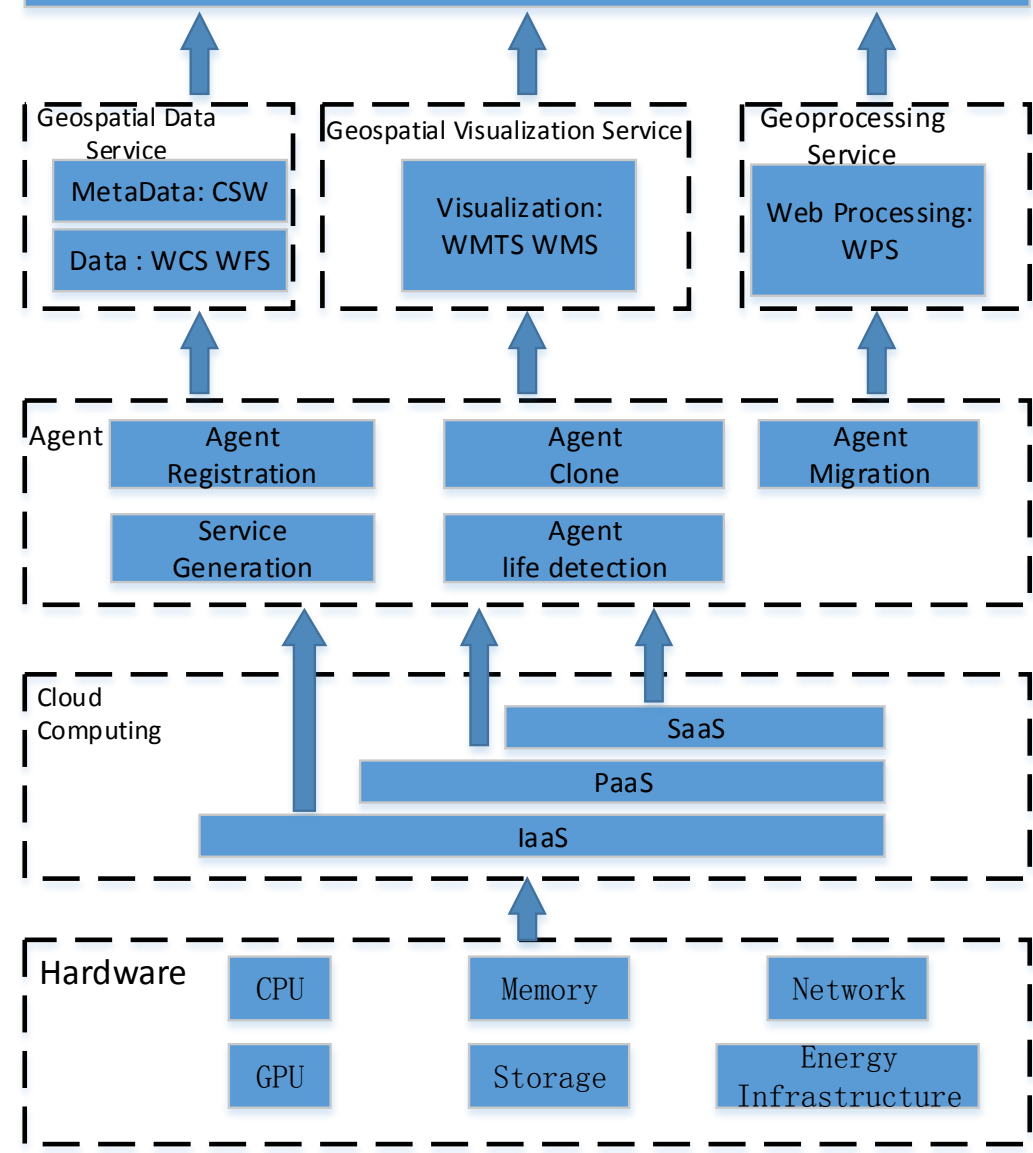

Figure 2 Agent- and Cloud-supported Geospatial Service Aggregation Architecture

Agent tier is built upon the Cloud and it offers the fundamental services, providing a mechanism to let the Agent move on the Cloud and communicate with each other freely. The fundamental services include agent registration and deregistration, agent-service conversion, agent migration, agent cloning, and agent life detection.

The geospatial service tier, in which all the geospatial services (e.g., geospatial metadata services, geospatial data services, geospatial visualization services and Web processing services, etc.) are converted by the Agent tier are working. These services are built automatically according to OGC specifications, which make the geospatial services have a high interoperability and can be combined intelligently in a standard manner.

The application tier is the use of the geospatial services by combining the geospatial services. Conventionally, geospatial services are aggregated manually into various applications such as Emergency Responding, Climate Changing, and Weather Forecasting applications. This tier is also the interface between the endpoint user and geospatial services.

\section{EXPERIMENTS AND DISCUSSION}

The tests on the Amazon AWS Cloud show the feasibility of the Agent and Cloud supported method. We build the prototype flood response system successfully as shown in Figure 3.

To demonstrate the superiority of the Agent and Cloudsupported method. We used $6 \mathrm{c} 3$.xlarge instances with moderate network speed; the net network data transfer rate is unstable from day to night and distributes from $0.1 \mathrm{Mbps} \sim 5 \mathrm{Mbps}$. The request timeout value was also set to $100 \mathrm{~h}$. We tested the SOAbased method and the presented method on the AWS Amazon Cloud. The performance test result is shown in Figure 4.

As shown in this figure, with the Agent and Cloud-supported method on the AWS Cloud, one request needs only $0.28 \mathrm{~h}$, but with SOA-based method, 43 hours were spent, which is almost a 153-fold greater execution time compared to the Agent and Cloud supported method. When there were multiple requests, the method spent $0.72 \mathrm{~h}, 3.5 \mathrm{~h}$ and $5.26 \mathrm{~h}$ when there were 5,10 
and 15 requests, respectively. However, all of the requests of the SOA-based method on the AWS Cloud failed because of the timeout, which means there more than 5 concurrent requests. The SOA- based method needs more than $100 \mathrm{~h}$ to make a decision, which is not proper for an emergency response such as flooding, earthquakes, etc. Hence, it is easy to draw the conclusion that the performance of Agent- and Cloud-supported service aggregation is far better than with the traditional SOAbased method, particularly when there is a low efficiency and an unstable network.

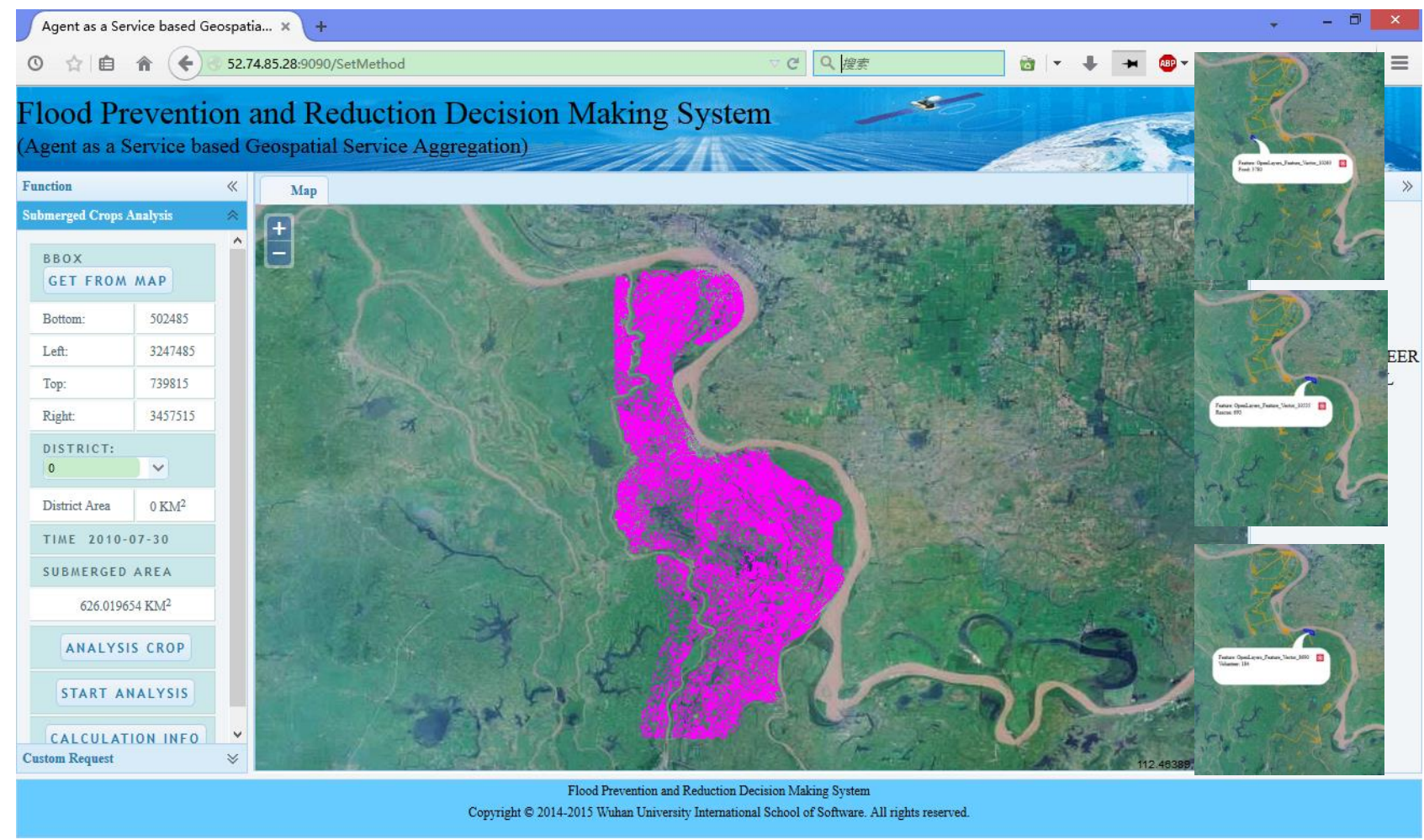

Figure 3 Flood Response Prototype System

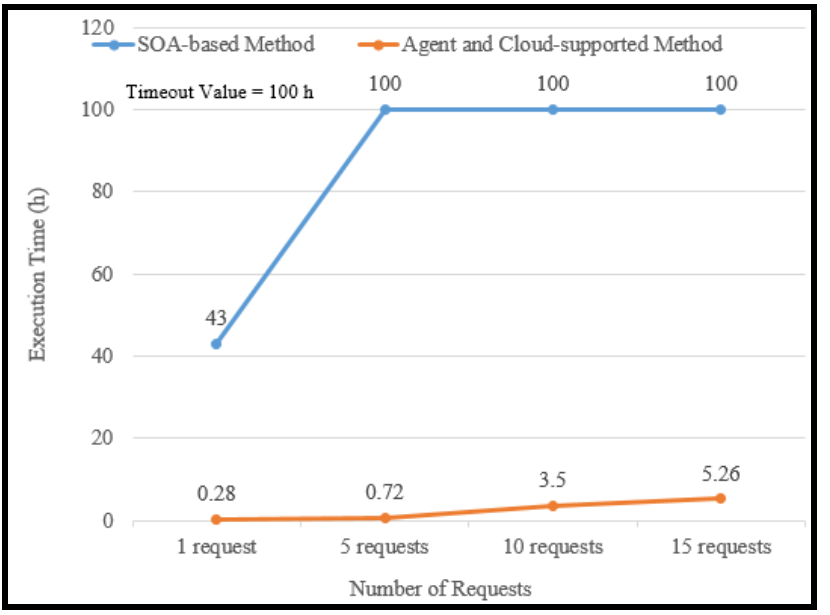

Figure 4 Performance Comparison

\section{CONCLUSION}

We proposed an Agent- and Cloud-supported service aggregation method to address the efficiency problems in constructing and executing a composite geospatial service for the response to flooding. Experiments on rapid response during a simulated flood in the Yangtze River basin demonstrated the feasibility and efficiency of the proposed method. This method can avoid the large-volume transfer of geospatial data and yield acceptable performance, even for multiple concurrent requests under unstable network conditions. This capacity will be critical for spatially distributed Big Data processing.

In the future, efforts will be made to enhance the robustness of complex service aggregation. In addition, the QoS of the geospatial service will be researched. Furthermore, the cost efficiency model of the Cloud-based geospatial service will be studied.

\section{ACKNOWLEDGMENTS}

The authors thank the editors and the reviewers for their outstanding comments and suggestions, which greatly helped to improve the technical quality of the manuscript. This work was supported in part by NSFC projects 51277167; "CAST Innovation Fund": the Study of Agent and Cloud Based Spatial Big Data Service Chain.

\section{REFERENCES}

M. Deng and L. Di, "GeoBrain Online Resources for Supporting College-Level Data-Intensive Geospatial Science and Engineering Education," in Proc. IEEE Geoscience and Remote Sensing Symposium (IGARSS), 2008, pp. IV-443-IV446.

P Yue, L Di, W Yang, G Yu, P Zhao. "Semantics-based automatic composition of geospatial Web service chains". 
Computers \& Geosciences, Vol.33, no.5, pp. 649-665, May 2007.

M. Deng and L. Di, "Building an Online Learning and Research Environment to Enhance Use of Geospatial Data," International Journal of Spatial Data Infrastructures Research, Vol.4, pp.7795, 2009.

M. Deng, L. Di, "Facilitating Data-intensive Research and Education in Earth Science - A Geospatial Web Service Approach," LAP LAMBERT Academic Publishing GmbH \& Co. KG, Saarbrücken, Germany, 2010 ISBN: 978-3-83839714-6.

M. Deng, L. Di, W. Han, A. Yagci, C. Peng and Gil Heo,"Webservice-based Monitoring and Analysis of Global Agricultural Drought," Photogrammetric Engineering \& Remote Sensing (PE\&RS), Vol.79, no. 10, pp. 929-943, October 2013.

P Yue, J Gong, L Di, "Augmenting geospatial data provenance through metadata tracking in geospatial service chaining," Computers \& Geosciences, Vol.36, no.3, pp. 270-281, March 2010.

R. S. Gray, G. Cybenko, D. Kotz, R. A, Peterson, D. Rus. "D'Agents: Applications and performance of a mobile-agent system," Software: Practice and Experience,Vol.32, no.6, pp. 543-573. May 2002.

L. Di, "A framework for developing Web-service-based intelligent geospatial knowledge systems," Geographic Information Sciences, Vol.11, no. 1, pp. 24-28, 2005.

A. Sayar, M. Pierce, G. Fox, "OGC Compatible Geographical Information Systems Web Services,” Indiana Computer Science Technical Report TR610, 2005.

L. Di, P. Zhao, W. Yang, and P. Yue, "Ontology-driven automatic geospatial-processing modeling based on web-service chaining," In Proceedings of the sixth annual NASA earth science technology conference, 2006, pp. 27-29.

C. Yang, R. Raskin, "Introduction to distributed geographic information processing research," International Journal of Geographical Information Science, Vol. 23, no. 5, pp. 553-560, 2009.

N Chen, L Di, G Yu, J Gong, "Geo-processing workflow driven wildfire hot pixel detection under sensor web environment," Computers \& Geosciences, Vol.36, no.3, pp. 362-372, March 2010.

L. Di, A. Chen, W. Yang, Y. Liu, Y. Wei, P. Mehrotra, C. Hu, D. Williams, "The development of a geospatial data Grid by integrating OGC Web services with Globus-based Grid technology," Concurrency and Computation: Practice and Experience, Vol. 20, no.14, pp. 1617-1635, March 2008.

C. Yang, Y. Xu, D. Nebert, "Redefining the possibility of digital Earth and geosciences with spatial cloud computing," International Journal of Digital Earth, Vol. 6, no. 4, pp. 297312, 2013.

D. C. Parkera, S. M. Mansonb, M. A. Janssenc, M. J. Hoffmannd \& P. Deadmane,"Multi-Agent Systems for the Simulation of Land-Use and Land-Cover Change: A Review,"
Annals of the Association of American Geographers, Vol. 93, no. 2, pp. 314-337, 2003.

Dijkstra, H. J. P. Timmermans, A. J. Jessurun, “A Multi-Agent Cellular Automata System for Visualising Simulated Pedestrian Activity," Theory and Practical Issues on Cellular Automata, pp.29-36, 2001.

D. G. Brown, and Y. Xie, "Spatial agent - based modelling," International Journal of Geographical Information Science, Vol. 20, no. 9, pp. 941-943, 2006.

R. Sengupta, D. A. Bennett. "Agent-based modelling environment for spatial decision support," International Journal of Geographical Information Science, Vol. 17, no. 2, pp. 157180, 2003.

D. G. Brown, et al., "Spatial process and data models: Toward integration of agent-based models and GIS," Journal of Geographical Systems, Vol. 7, no. 1, pp. 25-47, 2005.

I. Muller, R. Kowalczyk and P. Braun, "Towards agent-based coalition formation for service composition," in Proc.IAT, 2006, pp. 73-80.

H. Tong, J. Cao, and S. Zhang et al., "A distributed agent coalition algorithm for Web service composition," in Proc. IEEE Congress on Services, 2009, pp.62-69.

H. Tong, J. Cao, S. Zhang, M. Li, "A distributed algorithm for web service composition based on service agent model," IEEE Trans. Parallel and Distributed Systems, Vol. 22, no. 12, pp. 2008-2021, December 2011.

W. Tang, S Wang, DA Bennett, Y Liu, "Agent-based modeling within a cyberinfrastructure environment: a service-oriented computing approach," International Journal of Geographical Information Science, Vol. 25, no. 9, pp. 1323-1346, 2011.

Vescoukis V, Doulamis N, Karagiorgou S. A service oriented architecture for decision support systems in environmental crisis management $[\mathrm{J}]$. Future generation computer systems, 2012, 28(3): 593-604

J. Lehto, J. Rajamäki, P. Rathod, "Cloud computing with SOA approach as part of the disaster recovery and response in Finland," International Journal of Computers and Communication, Vol.3, no.6, pp. 175-182. 2012.

Rajamäki J, Rathod P. How standardized Utility Cloud Services and Service-oriented Architecture benefits in Public Protection and Disaster Relief?[J]. International Journal of Computers and Communications, 2014, 8: 86-93.

X. Tan, L. Di, M. Deng, etc., "Cloud-and Agent-Based Geospatial Service Chain: A Case Study of Submerged Crops Analysis During Flooding of the Yangtze River Basin" IEEE Journal of Selected Topics in Applied Earth Observations and Remote Sensing, Vol.8, no.3, pp. 1359-1370, 2015.

Haubrock S, Theisselmann F, Dransch D. Service-Oriented Architectures for Natural Disaster Management $[\mathrm{C}] / /$ Proceedings of the Joint CIG/ISPRS Conference on Geomatics Solutions for Disaster Management, CIG/ISPRS Joint Conference, Toronto, Conference CD. 2007.

Kussul N N, Shelestov A Y, Skakun S V, et al. The wide area grid testbed for flood monitoring using earth observation 
data[J]. Selected Topics in Applied Earth Observations and Remote Sensing, IEEE Journal of, 2012, 5(6): 1746-1751.

C. Yang, M. Goodchild, Q. Huang, D. Nebert, R. Raskin, Y. Xu, M. Bambacus \& D. Fay, "Spatial cloud computing: how can the geospatial sciences use and help shape cloud computing," International Journal of Digital Earth, Vol.4, no.4, pp. 305-329, June 2011.

Q. Huang, C. Yang, K. Liu, J. Xia, C. Xu, J. Li, Z. Gui, M. Sun, Z. Li, "Evaluating open-source cloud computing solutions for geosciences," Computers \& Geosciences. Vol.59, pp. 41-52, September 2013.

Q. Huang, C. Yang, K. Benedict, S. Chen, A. Rezgui \& J. Xie, "Utilize cloud computing to support dust storm forecasting," International Journal of Digital Earth, Vol.6, no.4, pp. 338-355, Janury 2013.
C. Yang, Y. Xu, D. Nebert, "Redefining the possibility of digital Earth and geosciences with spatial cloud computing," International Journal of Digital Earth, Vol. 6, no. 4, pp. 297$312,2013$.

P. Yue, H. Zhou, J. Gong, L. Hu, "Geoprocessing in Cloud Computing platforms - a comparative analysis," Cloud Computing, Vol.6, no.4, pp. 404-425, December 2012.

Z. Chen; N. Chen; C. Yang; L. Di, "Cloud Computing Enabled Web Processing Service for Earth Observation Data Processing," IEEE Journal of Selected Topics in Applied Earth Observations and Remote Sensing, Vol.5, no.6, pp. 1637-1649, 2012. 